\title{
Project-Based Learning (PBL) in Nepalese EFL Classroom
}

\author{
Ganesh Kumar Bastola \\ Lecturer \\ Department of Education, Mahendra Multiple Campus, Dharan, Tribhuvan University, Nepal \\ ganeshkumar.gb@gmail.com \\ DOI: https://doi.org/10.3126/dristikon.v11i1.39133
}

\begin{abstract}
Project-based learning is an innovative method to improve language skills. This study explores the five assets of project-based learning in the Nepalese context. It aims to examine how different dynamics of projects help students overcome their language learning difficulties and to show the relevancy of Project-Based Learning despite having many approaches and techniques in the anti-method era. Data for this study were collected both from primary and secondary sources. For eliciting primary information, I interviewed two of the EFL teachers and for the secondary data, I consulted research articles, books, dissertations, and reports related to project-based learning. I also employed the document analysis method in the paper since it is a theoretical review-based article where the researcher coded, thematized, and analyzed very sequentially to elicit meaning, gain understanding, and develop empirical knowledge about project-based learning. Innovative and learner-friendly curriculum demands for practical, pedagogical and project-based engagement in the $21^{\text {st }}$-century classroom which has seriously been ignored in the Nepalese EFL classroom. Noticing the unexplored status of the project-based learning approach, I stressed exploring the relevancy of PBL in the EFL classroom. More specifically, the prior methods used for achieving the expected outcomes of the paper are synthesis, deduction, analysis, interpretation and generalization. Findings indicate that project-based learning is an alternative tool and the best option for students to enhance their pedagogical content knowledge, creativity, and critical thinking.
\end{abstract}

Keywords: project, learning, teaching, practice, learners

\section{Introduction}

A project is simply understood as an enterprise that is carefully planned to achieve a particular objective individually or collectively. It can be intensive activities that take place over a short period or extended studies which may take up one or two hours a week for several weeks.

Beckett (2002) defines a project as, "a long-term (several weeks) activity that involves a variety of individual or cooperative tasks from developing a research plan, questions, and implementing the plan through empirical data that includes collecting, analyzing, and reporting data orally and/or in writing" (p.54). It is a multi-facet activity to help students gain a better 
understanding of content knowledge. Project-based learning has a lot of potentials to enhance $21^{\text {st }}$-century skills and engage students in real-world tasks (Bell, 2011; Han et al. 2015). It is considered a powerful teaching method that has extensive benefits (Thomas, 2010) both for students and teachers ranging from critical thinking to project management to self-confidence.

A project may start with a small drawing to having longitudinal research. The students develop multiple skills via multiple activities. It is mostly a focused activity where the learners initiate their project by the choice of the learners themselves and reach out to their expected aim. The learners succeed in their learning because they are very much freed to select the subject matter, prepare their timetable, and have an end product. It is primarily an approach to learning which complements mainstream methods and which can be used with almost all levels, ages, and abilities of students. For Haines (1989) project work is not a replacement for other teaching methods, neither is it something that is appropriate only to older or more advanced students. Thus, it is primarily an approach to learning which complements mainstream methods and that can be used with almost all ages and abilities of students. Moreover, Blumenfeld et al (2000), for example, described the process of project-based science as follows:

'The presumption is that students need opportunities to construct knowledge by solving real problems through asking and refining questions, designing and conducting investigations, gathering, analyzing, and interpreting information and data, drawing conclusions, and reporting findings' (p.150).

It is a comprehensive approach to language learning and teaching. Occasionally, scholars consider Project-Based Learning as Project-Based Language Learning (PBLL) and Project-Based Language Teaching (PBLT). However, the motto of PBL is to instruct students and help them enhance content-integrated techniques in their learning. Project-based language teaching makes the project central to the planning and teaching of the second or foreign language. The projects, which are long pieces of work involving investigation and reporting, require both linguistic and content abilities in the participants. The learners get opportunities to make use of the target language in real and real-like situations. Stoller (n.d.) states that teachers can employ various projects in a large class to handle and collaborate with learning outcomes. Therefore, projects help offer various opportunities for students in which they can develop their linguistic competence and cognitive understanding.

Similarly, Haines (1989) states that projects, in language learning, are multi-skill activities focusing on topics or themes rather than on specific language targets. Of crucial importance is the part which the students themselves play in the initial choice of subject matter and in the decisions related to appropriate working methods, the project timetable, and the eventual 'end product'. Moreover, the specific language aims aren't prescribed rather students are expected to concentrate their efforts in reaching out an expected goal. Therefore, it is 
potentially motivating, stimulating, empowering, and challenging. It usually leads to building student confidence, self-esteem, and autonomy also as improving students' language skills, content learning, and cognitive abilities.

English is taught and learned as an EFL in Nepal. Our classrooms are diverse, linguistically rich and they demand innovative curriculum, teachers' expertise in content knowledge, and learners' conscience towards learning. Offering learners autonomy with prior guidance and counselling, we achieve drastic changes even if the classes are boring and large. Learners consulting different sources such as textbooks, dictionaries, websites, seniors, and teachers can achieve a significant amount of success in their project individually or in the group. The learners in our context require context, concept, practice, and drills to build fluency, accuracy and meaning. The teachers support setting a goal for learners and all is done to make a tangible outcome. By its nature, the project-based approach is interdisciplinary and can be employed to teach many subjects and genres. Teachers simply bring locally and culturally available newspapers, poetry, novels, stories, diaries, travelogue, critics, journals, books, textbooks, portfolios, notes, reports, etc. to teach their content via projects. Teachers assist students to conceptualize mutual understanding, cooperative learning and project-based engagement in classroom practices. Therefore, either we teach grammar or literature, the projects simply encourage our learners to be responsive, responsible and interactive in their performance. The learners cooperate and agree on a theme for a project. They determine the outcome, collect information, a process that information and compiled it for analysis. After the successful analysis, they present and evaluate their project to examine whether they have been able to achieve their goals. Suppose, for example, teachers teaching poetry can easily engage students in a poetry-writing project. The teacher divides students into different groups, helps to set a goal and involve them in practice until and unless they complete their project. Likewise, the teachers teach anything difficult via a project-based approach for successful learning in their EFL context.

\section{Research Problems}

We know there have been significant changes in our methods and materials. We often practice a student-centred approach and bring locally and culturally available materials in our classroom context. There has been a paradigmatic paradigm shift in techniques and methodologies. The students in the $21^{\text {st }}$ century are not passive listeners rather they the active and energetic explorers. We left a one-fits-all approach in our classroom practice. Therefore, we do not treat and instruct our students the way our teachers did. We liberate our students to explore their views, perspective, experiences, creativity and allow to practice their potentials. Moreover, what students know and how they explore their creativity in the classroom are highly interpretive and contingent on knowledge of self, teachers, curricula and setting (Bastola, 2017). One of the best ways of exploring creativity is to offer a prior space for the 
learners to exercise the content knowledge via projects. Thus, project-based learning keeps on encouraging learners to raise questions, plan and carry out investigations, make an observation, and reflect on what they have explored (Jarrett, 1997). Taking reference to Jarrett (1997) as a theoretical gap, I destined to examine whether project-based learning enhances students' potentials. Besides that, I did not come across studies studying the usefulness of projects in our Nepali context. Moreover, a few of the research studies have been found abroad though their focus was on the theoretical dimension not on practical consideration. But then, by this study, I realized that there is an essence of research to be carried out to explore how teachers understand the values of projects, use them in classroom practice and how their project-based learning help students empower their learning in the classroom.

\section{Research Objectives}

The principal objective of this research was to explore the various assets of project-based learning in the context of Nepal. It aims to examine how creative use of projects help students achieve effective and meaningful learning and how it affects the overall performance of students in the language classroom.

\section{Rationale of the Study}

English is learned and taught as an EFL in Nepal. In an effective ELT classroom, the language learners require to accomplish different activities. The activities vary from student to student, level to level, and interest to interest. However, the students can be facilitated via four integrated projects; they are information and research projects, survey projects, production projects, and performance and organizational projects (Haines, 1989). We offer students various project-works based on their level and interest in their underlying goals. The projects are extended tasks that usually integrate language skills using many activities (Hedge, 2008). The rationale behind exploring the status and practice of project work is to help students in: planning, gathering information, discussing in the group, problem-solving, displaying information, reporting, and so on. Second language learners do not learn successfully simply by receiving transmitted facts, but they need to explore new ideas through conversations and writings in projects of various types.

Furthermore, Harmer (2007) also puts the rationale of using projects in the second or foreign language teaching and learning very extensively. According to Harmer, the students will look at books, consult websites, visit web quests, watch videos and perhaps, conduct their mini-research to complete their assignment. The teachers' guide, counsel, and offer plenty of exposure for boosting their level of confidence. Therefore, it helps enhance cooperativeness rather than competitiveness among and between students. The project thus becomes a perfect vehicle for skill integration and information gathering for second language acquisition. Therefore, projects are very useful to promote learner-centred teaching, processing instruction, 
collaborative learning, learner autonomy, and learning tasks through tasks. Knowledge about projects helps learners create and cater their own space in learning if they are given the freedom to choose topics and group members for writing or to work alone or in groups for final PBL production.

\section{Project-Based Learning and its Applicability in Language Classroom}

Enhancing creativity requires a strong zeal and passion with students and prior planning and enthusiasm with the teachers. The central part of the project is to focus on content learning instead of on specific language targets. Teachers are expected to manage real-world material and learner-friendly topics. It mostly prioritizes students, their projects, and help students work on their own, or in pair or small groups. Moreover, the teachers in project-based learning help students in offering support and guidance throughout the project. Teachers share their understanding, ideas and show their expertise in instructing the learners in the classroom. It can be employed from beginners to advanced proficient learners.

It helps the teachers to authenticate and integrate skills and processing information from varied sources. It culminates in an outcome (e.g., a public speaking, a billboard session, a bulletin-board display, a report, or a stage performance) which will be shared with others, giving the project a real purpose. The value of the project, however, lies not just in the final product but in process of working toward the endpoint. Thus, project work has both a process and product orientation and provides students with opportunities to specialize in fluency and accuracy at the different project-work stages. No matter at which level the students pursue their knowledge. It matters what and how they pursue. The learners are guided by certain steps to accomplish project work. The steps sometimes may be more or less it depends upon the subject matter of the project or the theme of the project that the participants have projected. Taking reference to Stoller (nd.), the following steps are viable in instructing students in their learning.

\section{Step- 1 Agree on a Theme for the Project}

The students are offered a wide range of subject matter. We facilitate them to decide or agree on a theme. Based on their section of the project title, the students initiate their project work.

\section{Step- 2 Determine the Final Outcome}

The learners further discuss to determine the outcome in the second stage.

\section{Step- 3 Structure the Project}

The learners, with the help of their instructor, revisit their determined goal and prepare an overall plan for learning.

\section{Step- 4 Information Gathering}


The learners gather information very acutely. The prior source of information is tacit and embodied where the learners frequently consult their instructor and proceed ahead with their project.

\section{Step- 5 Information Compilation}

Then, they further compile information that they collected pertaining to their expected goals.

\section{Step- 6 Information Reporting}

As a product-based reporting, the learners report their gathered information very succinctly and vividly.

\section{Step-7 Evaluate the Project}

Finally, in the end, the learners evaluate their project concerning the specified purpose of their learning.

Therefore, these steps empower learners to actively participate in their projects. The skill-based projects cater to all abilities within a class. The teachers re-integrate language and establish a context which balances the need for fluency and accuracy. Our Nepalese EFL/ESL learners are found to be divergent in their learning potentiality. They come from different cultural, linguistic, and social backgrounds and we need to treat them accordingly. Each learner has their way of learning even if there are three different types of learners in the classroom. The fast learners learn very faster, average learners learn in an average form and the slow learners learn very slowly. However, project work potentially helps every learner to work at their own pace and explore their creativity.

\section{Review of Literature}

There are several dimensions of engaging learners in the EFL classroom to enhance their creativity and critical thinking. Among them, project-based learning is very much crucial for the holistic development of learners. Indeed, project works enable, motivates, and encourages learners of different abilities to work cooperatively on tasks of equal value. Haines (1989) researched entitled Resource materials for teachers highlighted the essence of projects. The study further focused on the assets of the non-linguistic tasks e.g., design, illustration, organization, and handling equipment for instructing students to accomplish their work enhancing creativity in their learning. The project helped students develop their designing skills, illustrating skills, organizational skills, and knowledge of handling equipment. The result indicated learners' active participation made their learning lively, effective, and meaningful.

Similarly in another study Supe and Kaupuzs (2015) in their study, "The Effectiveness of Project-Based Learning in the Acquisition of English as a Foreign Language" highlighted the project-based approach as a student-centric approach in which students are motivated in using language in real-life situations involving a great number of participants' skills, knowledge, and 
expertise. The study further claimed that students learned better when they are involved in a group with specified project work and motivation towards their learning.

Aslanides et al (2016) in their study Advantages, disadvantages, and the viability of projectbased learning integration in engineering curriculum: The Greek case highlighted the viability of project integration in teaching and learning. They further claimed that project-based learning is a shift from classical paradigm to modern dynamics where the students are allowed to question, research, and apply in their real-life situations. The result indicated that students get an opportunity to explore their inner potential in questioning, critical thinking, and problemsolving.

Aksela and Haatainen (2019) in their study Project-based learning (PBL) in practice: Active teachers' view of its advantages and challenges highlighted the essence of project-based learning. They further shared those projects assigned to the students become influential to enhance, engage and boost students' potentials. The project work doesn't only help those, who have a strong linguistic repertoire rather helps relatively weak concerning their formal linguistic achievement. The results indicated that the projects help students to develop cooperative learning and critical thinking.

The aforementioned studies helped me construct a strong understanding of the effectiveness of projects and project-based teaching. For them, project work remained the most reliable learner-centred approach in language teaching and testing. Pertaining to $21^{\text {st }}$-century skills, learners in classroom teaching must meet some requirements for good going. In doing so, I came across different studies carried out in and around the globe and found that they solely focused on the projects either facilitating learners in pair work or the group. The students were more facilitated in their projects and they were allowed to demonstrate their potentials offering them ample opportunity for better learning outcomes. We, teachers, should focus on cooperative learning rather than competition.

\section{Local-global Interface}

Teaching and learning the English language as a foreign language require some explicit theories, methods, and approaches that help teachers develop in their students what we often call communicative competence in the EFL classrooms. Language learning is concerned with enhancing learners' capabilities inculcating language skills to practice behaviours and pedagogical practices (Harmer, 2007). But in our Nepalese EFL (English as a foreign language) context, the practice is not made properly. We search for available literature, browse various re/sources, attend different conferences and seminars nationally and internationally. We also train teachers in various ways for various purposes but we lack in implementing their practices in the real classrooms. As a result, we fail to provide succinct scaffolding to the learners. And learners also do not entertain out lectures throughout their classroom learning. Thus, we need to 
focus on student-centred activities such as project work, group work, and so on. For successful learning, we require to substitute outdated and uninteresting textbooks and syllabi loaded with old literature (Gautam, 2015). Lack of exposure to real-world English 'which does not tally with what students find outside' is another vibrating issue for him. Besides that, exam perpetuating rote-learning, and practising the status-quo in every asset of our teaching and learning hindered creativity and critical thinking among students.

Indeed, we find distinct ideologies in teaching English as a foreign language globally. We adopt and adapt different approaches in our context but we fail sometimes to acknowledge the diversity of our students and address accordingly. We lack in analyzing the content and materials which are prepared for the native speakers may not entail the positive vibes in addressing the student's problems and diagnose them in our EFL setting. For this, the teacher's commitment also plays a pivotal role in the EFL classroom. Therefore, a teacher in the language classroom has to amalgamate all the aspects and seek for appropriate strategy to practice project works in the EFL classroom. It means to say that the teacher has to contextualize his/her teaching situation according to the needs and interests of the learners. Thus, the present scenario of Nepalese EFL seems to be very emerging and developing but due to certain issues such as over-crowded classroom, lack of physical facilities, students' motivation, teacher's commitment, and so on have created an obstacle to addressing EFL/ESL classroom contextually, appropriately, and meaningfully.

\section{Materials and Methods}

I employed a qualitative approach in my paper. The data were collected from both primary and secondary sources. As a qualitative researcher, I have employed an interpretative paradigm to explore different perspectives of the participants in the study. I employed the document analysis method as well for the analysis and interpretation of secondary data which were collected consulting research articles, books, dissertations, different websites and reports related to project-based learning. Meanwhile, I linked my conceptualization with Bowen (2009) for document analysis which is a systematic procedure for reviewing or evaluating documentsboth printed and electronic materials. Moreover, document analysis is a form of qualitative research in which documents are interpreted by the researcher to raise voice and meaning around an assessment. Two teachers were purposively selected for the interview. Teachers practising project-based approaches were made to share their reflections in interviews. I understood that teachers' experiences, complexities and human centeredness could not be captured just through employing mathematical tools, therefore, I interpreted both forms of data using interpretive notion and document analysis procedures of the coding and thematizing process to examine closely and interpret justifiably. Thus, being closer to Corbin and Strauss (2008) I examined, analyzed and interpreted both primary and secondary data to elicit meaning, gain understanding, and develop empirical knowledge. The prior methods used for achieving 
the expected outcomes of the article are analysis, synthesis, induction, deduction, interpretation and generalization.

\section{Results and Discussion}

Gaining various insights from literature, interviewing two of my research participants, and decade-long prior experiences as an EFL teacher helped me to generate five themes to discuss the relevancy of PBL in the Nepalese context. The following themes have been discussed further; they are: a) Effective implementation of curriculum, b) enhancing active and creative atmosphere, c) engaging in cross-cultural understanding, d) empowering learners, and e) evaluating learning outcomes. These five themes are not the panacea but considerable components in practising project-based learning to develop competence as well as improve the performance of the students.

\section{Effective Implementation of Curriculum}

Replicating my own experiences in the field of teaching, I believe that teachers should be dynamic, creative, and qualified to handle $21^{\text {st }}$-century students and to implement the curriculum effectively. The successful implementation of the curriculum depends mostly on the quality of assessment and testing (Das et al., 2014). The data from both sources inculcated that the quality of assessment and testing relies on the quality of qualified teachers', awareness of concerned stakeholders in education, and the students themselves. There is a linear relationship between the failure of English language teaching and curriculum implementation and inappropriate assessment methods in our Nepalese context. The data further indicated that one of the critical issues of the curriculum implementation was the exclusion of student-centred approaches in their teaching-learning process. The data revealed that the successful implementation of the curriculum requires teachers' expertise, a student-friendly environment, technocratic approaches in teaching and project-based learning. Let me share with you two excerpts from two of my participants using the project-based approach in the EFL classroom. One of my participants, Sagar(pseudonym) shared,

During my classroom practice, I prepare a lesson plan, collect available materials, discuss with my students regarding the possible topic for discussion because I consciously pay proper attention to implementing the curriculum. Suppose, for example, the curriculum expects students to prepare an academic calendar, lesson planning and book and article reviews in the university course. And I involve them to work further in a project to prepare academic calendar, lesson planning and book and article reviews and assist them in every affair of their difficulties.

Here, Sagar's indication explored that the effective implementation of the curriculum was possible only when teachers engage students in the projects. The data from secondary sources also entailed that a project-based approach remained a milestone for both teachers and 
students to develop cooperative thought and pedagogical engagement and academic success. The project-work remained footprint to assess curriculum, either of elementary or of postgraduate level, prioritizing some specified steps from initiating essential questions, designing a plan for the project, creating a worksheet, monitoring students project and progress, assessing their output, and evaluating their work experience (Rahman, Pandian, \& Kaur, 2018a). The essential property of the project-based approach pinpointed that students get maximum opportunities to practice further for their holistic development. Supporting the similar notion, my participant Aasha (pseudonym) shared thus;

I always engage students in project work either I teach lower grade students or university graduates. For effective experimentation of the course curriculum, I set a mindset, discuss with students and draft a step-wise procedure. When my students work together and cooperate on the same project, they earn plenty of exposure and skills as per the demand of the prescribed curriculum. And their learning entails that they learn what they are supposed to learn.

The data from both participants Sagar and Aasha along with the secondary sources indicated that student learns better when they practice 'learning by doing approach'. The data revealed that the creative use of projects not only supported students to accomplish their project works but also assisted them to have effective implementation of the curriculum. The students, suppose for example, in project-based learning, involved themselves in role-playing, writing, and reading. They artistically brought innovation in research skills, presentation skills, cooperative skills, and collaborative skills, therefore; they easily enhanced effective and meaningful learning. The potential learners enhanced their skills via projects and their learning was shaped through various projects and activities designed for the $21^{\text {st }}$-century learners. The project-based approach replaced the traditional chalk and talk method in the EFL classroom and blended student-friendly method for meaningful learning. Thus, the data indicated that projectbased learning eased the effective implementation of the curriculum in the EFL classroom.

\section{Enhancing Active and Creative Atmosphere}

Exploring students' potentials demand technological and pedagogical engagement in $21^{\text {st }}$ century classrooms. The students use technology and collaborate to solve their problems themselves creatively in a foreign language learning context via projects. The data provoked that making the students active, energetic, and creative means engaging them in project-works to make them responsible in their learning. For Aslanides et al (2016) project works are useful in enhancing student's creativity via questioning, researching, and applying their knowledge in a real-life situation. They further entailed that the students got better opportunities to explore their inner potential in questioning, thinking critically, and solving their problems. The data revealed that the role of teachers remained much concentrating on designing prior projects for 
students' learning and the genuine task for students was to work actively to show the progressive influence in their learning.

The data highlighted that the projects help students explore their potentials and develop selfesteem and confidence. Thus, project works allowed learners to enhance $21^{\text {st }}$-century skills including critical thinking, collaboration, creativity, and cooperation because they remained active and interactive in every works, they involve in. The creative use of projects helped students learn any content such as a report, research, academic and creative writing. Here is another experience of a participant Sagar who shared the experiences of employing a projectbased approach in his classroom. He further shared;

I randomly ask my students to share their experiences about their likes and dislikes. After collecting their experiences, I actively encourage them to work on a project. For example, if I have to teach poetry in my class, I involve every student in the same project and asked for an equal contribution to form a piece of poetry. However, I show a sample for them and they bring their creativity and present making a pictorial representation in the class via projects. However, sometimes below average students may remain silent in project work and they may not achieve the expected learning outcome. To be true, I support them in such a context.

Such practice indicated that there is a prior chance of enhancing creativity and boosting up their confidence. They reviewed data and my participant Sagar stated when they ask their learners to work in pairs or groups, or projects, certainly they develop the fundamental skills of interaction with their co-learners. Aasha, having a long run teaching experience and utilizing her knowledge in projects shared that the project-based approach is against the 'one-fits-all approach where teachers are expected to switch different methods as per the demands of the content course. She further noted;

I often use the project-based approach in my lower grade students. Pertaining to the demands of the curriculum, I assist my students in every respect, encourage them to accomplish practical projects either they practice drawing, reporting writing, role-playing or they orally interact for a communicative purpose. They shape and develop creativity via authentic projects.

The data from both primary and secondary sources indicated that the creative and authentic use of projects helped students enhance creativity, strengthen their understanding and practise pedagogical projects for their learning. The learners developed communicative competence, enhanced interactivity and got a chance to prove themselves as unique individuals since they had their duties, responsibilities, and task to accomplish in the project work. The data further revealed the active learners in projects discussed on a topic, went to the field to collect data, built a good rapport with the respondents, elicit significant information and prepare a final report understanding the ground realities. The creative use of knowledge and skill remained paramount in every project for the learners to achieve the expected outcome. Each 
learner interacted with the other and got more ideas about their tasks, therefore; project-works have been far more insightful, alarming, and meaningful in the EFL classroom to create and cater active and creative atmosphere in learning.

\section{Engaging in Cross-cultural Understanding}

Learning is a continuous process. Learned skill has to teach personal and social responsibility. Acknowledging social practices and cultural assets, every child has to be taught socio-cultural understanding. For this, the project work is to make the learners familiar with the foreground realities and construct their way of understanding. However, the data showed, among different alternative approaches in recent practices in language teaching and testing, project work has been considered as one of the best assessment tools in empowering learners in their learning achievement. Facilitating learners to planning, designing, and implementing various tasks have been crucial to overcoming with an appropriate solution. Aksela and Haatainen (2019) focused on the essence of project-based learning in which learners are taught cross-cultural understanding to enhance, engage and boost students' potentials. The data indicated that knowing about others' cultures was important. The learners knew many dimensions of social and cultural practices, the project-work offered them the prior experimentation skills and a mindset for comparative study from one particular group of people to other. The reviewed literature pointed that the learners enhanced productive ideas and skills through projects when they are asked to work in a group collaboratively. Likewise, Aasha, another participant put forward her experiences regarding cross-cultural understanding and insisted thus;

I offer some reading materials about people, culture, costume and society. I also provide them with a sample project and instruct my students to prepare a similar project exploring significant information from another culture. Suppose, if I have to teach greetings, I engage them in the different sources from all around the world and motivate them to produce a project examining the sample provided. Therefore, they become able to enhance cross-cultural understanding.

The data further indicated engaging students via language-related project-works such as writing a biography of a person, giving a police description of the event and preparing a case-study file, etc. required a strong linguistic repertoire, communicative skills, cultural awareness and social understanding, achieving both interpersonal and intrapersonal abilities (Thomas, 2010). In course of our interview session, my participant Sagar pinpointed the essence of cross-cultural understanding and shared;

I often motivate my students to work in pairs and explore new information. Suppose, for example, if I have to teach my students about cultural and social practices of the world, I engage them in a project. They prepare a mindset, work together and reach a conclusion with the help of the project they work together. 
The data revealed that the students work independently at some point of their project work and they collaborate for meaningful learning in some other points of their project. The students learned several innovative ideas and skills and other interdisciplinary assets from different socio-cultural contexts. The data further envisaged that the creative use of project work has changed the role of teachers and students. The teachers as a transmitter of knowledge and skills have been replaced in recent era and they have been treated as a facilitator in the learning process. The projects-based approach made students more active, energetic, and enthusiastic to accept the challenges. Therefore, project work paved the way for students to succeed ahead in their language classroom.

\section{Empowering Learners}

Project-based learning concentrates much on students' activity in their classroom. The students are empowered to make a continuous effort involving in different projects. Active participation of the students and offering similar environments provoke a better and greater learning atmosphere. The data stated that the participants actively choose content, set their plan, initiate their work, and accomplish the projects themselves. In doing so, they took the charge of their learning, discover their potential, and develop the thought of learning as fun. The students developed cooperative assistance and collaborative thought and they are nurtured through pair/share and group activities, they made most of the decisions: contents and processes by themselves, and they generated self-confidence during the process and so on (Gautam, 2015). He further pinpointed that the teachers' motivation is pivotal for PBL intervention, and trust in the learners' capabilities of 'learning to learn is crucial'. One of my participants, Sagar further shared,

I often start my class with a prior revision of the last lesson we had. I collect students' perspectives, envisage methodologies and involve them in the discussion. But importantly, the project topics are often finalized by the group of the students, collect data by themselves and draft outcomes on their own. The students perform better when they are empowered encouraging and supporting in their projects.

The data stated that empowering students in their learning has been pertinent to every facilitator for meaningful learning. It has been noted that the students in project work could be motivated to explore their linguistic cognition, project-oriented skills and pedagogical content knowledge. Moreover, projects allowed learners to question, explore and finalize their real outcomes. The data also highlighted that the students at some point feel irritated to work on a project with some content courses but they were equally anxious to explore new information in and around his/her society. My participant Aasha shared further that the project-based approach has been learner-friendly and appropriate in the EFL context. She further noted; 
No matter how boring my students are. No matter how large my classroom is. But it matters what I teach and how I teach. Therefore, I search for the best project to empower my students in student-centred projects. They collaboratively work in a group and generate a new body of knowledge.

The aforementioned data invoiced that teachers' creative effort, assistance in their confusion, and positive counselling affects project-based learning. The artistic presentation of the project empowered both teachers and students to be motivated, regular, and active in their learning. The data further indicated that the more regular and active the participants are, the more productive their results have been. However, project-based learning helped students develop questioning abilities, writing skills, practice a lot through projects and generate a new body of knowledge. Therefore, it has been noted no matter at which level the students are, no matter what particular subjects have been taught, but it mattered how have we been able to instill ownership in their learning to reach their destination.

\section{Evaluating Learning Outcomes}

The teaching-learning process has specified learning aims and expected outcomes. In the EFL context, evaluation is one of the significant components to examine students' performance. To examine students' performance, it is required to analyze students' involvement in a project. The data showed that the students in project-based learning have been competent and successful because of their active and energetic participation in learning. To examine how project-based learning worked, we teachers in the $21^{\text {st }}$ century must mark some criteria and process students' learning accordingly. The data from both sources revealed that all the teachers encourage students to work collaboratively in the project and ask to analyze the overall performance by themselves in the language classroom. Beckett (2002) advocated that it is far easier to evaluate learners learning outcomes via project work because some projects create opportunities to exercise their language skills, note-taking skills, and communicative competence. For my research participant Sagar, evaluation is significantly important to envisage the effectiveness of project work and he advocated thus,

I often examine my students' performance regularly. In doing so, I provide different opportunities for learning in projects. They practice 'learning by doing' and accelerate their understanding. When they complete their practical and project work, they are asked to sit for oral interaction and written tests at the end.

The data indicated that project-based learning has been the better tool to develop the learner's overall performance. The data pinpointed that every learner in project-based learning starts working from agreeing on the theme for the project, determine the outcome, structure the project, collect data, compile them meaningfully and report at the end and evaluate themselves whether they have been successful. They enhanced ideas of conducting a project, develop 
confidence through interaction and gain cooperative skills and abilities. Learners' involvement in some projects helped them to know better about their learning. The learners at some point became able to realize what they learned and what they have yet to learn. Therefore, the creative use of the project assisted every individual teacher to examine how their teaching has been meaningful and effective in the $21^{\text {st }}$-century classroom. Aasha, having a better experience in project-based learning, insisted on the relevancy of evaluation projects approach and shared,

I teach searching for the best method to teach. My students engage themselves in different tasks from designing a brochure, pamphlets, posters, calendars, menus, etc. They are offered to work on different projects and I evaluate based on the performance they performed in their projects.

The data revealed that we teachers should be able to set a goal for teaching and act accordingly. The multiple problems of the students are to be addressed in the classroom giving them a vivid picture of some possible guidelines. And projects, most importantly, pave the way for obtaining better written and oral skills. The data further indicated that projects are helpful for teachers in addressing content-related problems, discipline-related issues and technology integrated curriculum pertaining to multiple intelligences and social and cultural backgrounds of the students. The data further pointed out that the teachers in the project work empower students to eliminate their absenteeism, help them develop a cooperative environment and enhance their learning strategies, develop a mutual understanding for mutual benefit among and between their co-partners. Thus, project-based learning should have been considered to evaluate the actual performance of students in doing their projects.

\section{Findings}

The findings indicate that for effective implementation of curriculum at the present scenario, there should be the effective practice of project-based approach and there should be active and creative atmosphere, students' engagement in cross-cultural understanding, empowerment of learners, and proper evaluation procedures of learning outcome. Thus, project-based learning should have equal balances between the nature of the curriculum, qualification of the teachers, enthusiasm of the students, and prior assessment procedure for enhancing learning outcomes in $21^{\text {st }}$-century classrooms. The study further reveals that for meaningful and practical knowledge, there should be project-based teaching-learning procedures where students accelerate their creativity and critical thinking abilities. However, the project-based approach, having an interdisciplinary feature, has not been prioritized for students' engagement. There has been serious negligence to enact a learner-friendly curriculum that demands learner's active participation in the pedagogical project. The unexplored status of project-based learning reveals that there is the essence of project-based learning in the EFL classroom. 
Regarding the effective implementation of curriculum, teaching-learning activities should go along with projects, and those projects should teach them problem-solving skills and work ethics. The findings reveal that effective teaching-learning starts with a task and reaches the expected outcomes. The students develop a habit of working independently, build teamwork, group work skills, and enhance cooperative learning skills. Moreover, they gain experiential learning by doing various projects along with open-ended questions. In the project, they get enough instances of scaffolding, rigorous feedback, and quick revision of the plan for second language processing and self-reflection. Therefore, the students and teachers in projectbased learning are expected to practice different tasks for the creative use of projects which is imperative to achieve expected outcomes in classroom practice.

\section{Conclusion}

The influence of prior learning experiences on project-based learning entails primarily on the achievement of realistic objectives, and then on the language that is needed to achieve those objectives. Project-based learning treats language as an instrument to complete a given project. The project-work gives plenty of opportunities for communication in authentic contexts and gives the learner freedom to use the linguistic re/sources $\mathrm{h} / \mathrm{she}$ has, and then reflect on what they learned. The most important thing about the project work is to use what works best for us and our learners in the language classroom.

Finally, the paper concludes with the idea that project-based approaches help the students reach into 'real-world' context. The study points out that the students need to be exposed to a variety of re/sources for projects such as libraries, the internet, lecture notes, audio and visual materials to help them develop their potentials, therefore, they gear up their understanding. The available data indicates that for the overall performance of students in their learning, there should be active participation, regular engagement and dedication in project work by which they develop collaborative skills, managerial skills, content knowledge, and pedagogical strategies.

\section{References}

Aslanides, C. dD., Kalfa, V., Athanasiadou, S., Gianelos, Z. \& Karapatsias, V. (2016). Advantages, disadvantages and the viability of project-based learning integration in engineering studies curriculum: The Greek case. $44^{\text {th }}$ SEFI Conference, 12-15 September 2016, Tampere, Finland. https://www.researchgate.net/publication569843

Aksela, M. \& Haatainen. O. (2019). Project-based learning (PBL) in practice: Active teachers' views of its advantages and challenges. A Conference Paper Presented at the $5^{\text {th }}$ International STEM in Education Conference at Queensland University of Technology, Australia. 
Bastola, G. K. (2017). Exploring English Teachers' Pedagogical Capital: A Narrative Inquiry. [An M. Phil Thesis Submitted to School of Education, Kathmandu University], Hattiban, Lalitpur.

Beckett, G. H. (2002). Teacher and students' evaluations of project-based instruction. TESL Canada Journal, 19(2).

Bell, S. (2010). Project-based learning for the 21st century: Skills for the future. A Journal of Educational Strategies, Issues and Ideas 83(2), 39-43. https://doi.org/10.1080/000986509

Blumenfeld, P., Fishman, B.J., Krajcik, J., Marx, R.W. \& Soloway, E. (2000). Creating usable innovations in systemic reform: scaling up technology-embedded project-based science in urban schools. Educational Psychologist, 35(3), 149-164.

Bowen, G. A. (2009). Document analysis as a qualitative research method. Qualitative Research Journal, 9 (2), 27- 40. doi:10.3316/QRJ0902027

Corbin, J. \& Strauss, A. (2008). Basics of Qualitative Research: Techniques and Procedures for Developing Grounded Theory (3rd ed.). Thousand Oaks, CA: Sage

Das, S., Shaheen, R., Shrestha, P., Rahman, A., \& Khan, R. (2014). Policy versus ground reality: secondary English assessment system in Bangladesh. Curriculum Journal, 25 (3), 326-343. https://doi.org/10.1080/09585176.2014.909323

Gautam, G. (2015). Learners' autonomy in large classes through project-based learning: A collaborative action research. Submitted for UGC, Nepal.

Haines, S. (1989). Resource materials for teachers. England: Longman.

Han, S. Y., Yalvac, B., Capraro, M. M., Capraro, R. M. (2015). In-service teachers' implementation and understanding of STEM project-based learning. Eurasia Journal of Mathematics, Science and Technology Education 11(1), 63-76. https://doi.org/10.12973/eurasia.2015.1306a

Harmer, J. (2007). The practice of English language teaching. London: Pearson Longman. Hedge, T. (2008). Teaching and learning in the language classroom. Oxford: OUP. Jarrett, D. (1997). Inquiry strategies for science and mathematics learning. Portland, OR: Northwest Regional Laboratory. http://educationnorthwest.org/webfm_send/748* Rahman, M.M., Pandian, A., \& Kaur, M. (2018a). Factors affecting teachers' implementation 
of the communicative language teaching curriculum in secondary school in Bangladesh. Qualitative Report 5(23).

Stoller, F. L. (nd). Looking into the future: Project-based learning in EFL classrooms.

Supe, O. \& Kaupuzs, A. (2015). The effectiveness of project-based learning in the acquisition of English as a foreign language. Society, Integration, Education, 2 (458). http://dx.doi.org/10.177770/sie2015

Thomas, J. W. (2010). A review of research on project-based learning. CA: Autodesk Foundation. Retrieved from http://www.bie.org/object/document 